\title{
BIOGEOGRAPHY OF THE FAMILY MIMOSACEAE IN SRI LANKA
}

\author{
SN Wickramarathne and GP Ekanayeke \\ Department of Geography, University of Peradeniya, Perdeniya
}

The objective of the present study was to investigate the geographical distribution of the Mimosaceae family In Sri Lanka. Some primary data for the study were obtained during field visits to different places, through perional communications with Ayurvedic doctors and residents of different geographical areas. Als $s$ incorporated were secondary data and information form several sources. The distribution of each genus and species was mapped by a GIS to show their distribution on a district basis, As the study revealed, the Family Mimosaceae contains 16 Genera (none of them endemic). Vine are indigenous (although they contain some exotic species); Acacia, Abarema, Adenxnthera, Albizia, Cathormion, Dischrostachys, Entada, Neptunia and Painteria. The remaining seven genera are exotic; Desmanthus, Leucaena, Mimosa, Pithecellobium, Prosopis :amanea and Vachellia.

The genera Acacia, Albizzia and Mimosa can be considered widely occurring in all zones. Cathormion and Prosopis are confined to the arid zone. Dischrostachys and Pithecllobium are in the dry and wet zones. Desmanthus, Vachellia, Neptunia and Painteria are confined to the dry zone. Entada, Leucaena, and Saminea are in the dry and intermediate zones. Abarema and Adenanthera in the intermediate anc wet zones. Acacia is the genus having the largest number of species (19), followed by Albizia(6). Both Abarema and Mimosa contain three species each. Adenanthera and Neptunia have 2 species each. The remaining 10 genera have one species in each genus.

Thus, altogether three are 45 species; six endemic, 19 indigenous and 20 exotic (including, naturalized species). Out of the six endemic species five are in the wet zone. Abarema abeywickramae, A. bigemina, Acacia lankaensis, Albizia lankaensis and Adenanthera bicolor. One species, Painteria nitida is confined to the north central and eastern parts of the Dry zone. Out of the 19 indigenous species e:ght are Acacia species mainly in the arid and dry zones. There are four indigenous $A$ lbizia s ecies occurring in all zones expect the arid zone. Two are Neptunia species both in the dry zoie wetlands. The remaining five are Abarema subcoriacea and Adanathera pavonina (mid contry wet zone), Cathorimion umballatum and Dichrostachys cinera (dry zone) and Entada pusaetha in all zones except the arid zone. Of the twenty exotic species ten are Acasias growing in the hill country there is only one exotic Albizia species and it close in the mid and low country tot zone. There are Mimosa species one wide, one in the hill country and the third invasive (M. pigra). Of the remainning six, Desmanthus virgatus, Pithecellobium dulce and Vachellia farnesianar in the dry zone. Leucaena leucocephala occurs widely. Samanea saman is an avente tree in dry and wet zones. Prosopis juliflora is invasive, although confined to the arid zone

46 Proceedings of the Seventh Annual Foresty and Environment Symposium 2001 University of Sri Jayewardenepurs, Sri Lanka 